\title{
Metabolic Outcomes 1 Year after Gastric Bypass Surgery in Obese People with Type 2 Diabetes
}

\author{
Yared N. Demssie $^{a} \quad$ Jhalini Jawaheer ${ }^{a} \quad$ Seleena Farook ${ }^{a} \quad$ John P. New ${ }^{a}$ b \\ Akheel A. Syed ${ }^{a, b}$ \\ ${ }^{a}$ Department of Obesity Medicine, Endocrinology and Diabetes, Salford Royal NHS Foundation Trust and

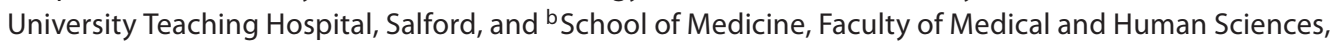 \\ University of Manchester, Manchester, UK
}

\section{Key Words}

Bariatric surgery $\cdot$ Roux-en-Y gastric bypass $\cdot$ Glycosylated haemoglobin • Obesity • Type 2 diabetes mellitus

\begin{abstract}
Objective: To assess metabolic outcomes in obese people with type 2 diabetes (T2D) in the first year following gastric bypass surgery. Subjects and Methods: Forty-nine obese patients with T2D who had undergone gastric bypass surgery 12 or more months previously were identified. Body weight and glycosylated haemoglobin $\left(\mathrm{HbA}_{1 \mathrm{c}}\right)$ pre-operatively and 3, 6 and 12 months postoperatively, changes to glucose-lowering therapies, and blood pressure (BP) and total and high-density lipoprotein (HDL) cholesterol pre-operatively and 12 months postoperatively were recorded. The primary outcome measure was change in $\mathrm{HbA}_{1}$; secondary outcomes included changes in BP and lipid profile. Results: The mean pre-operative body weight was $141.4 \mathrm{~kg}$, the body mass index 49.4 and $\mathrm{HbA}_{1 \mathrm{c}} 8.1 \%$. The mean postoperative percentage of excess body weight loss at 3, 6 and 12 months was 39.0, 53.9 and 71.1 with reduction in $\mathrm{HbA}_{1 \mathrm{c}}$ to 6.6, 6.2 and $5.8 \%$, respectively $(p<0.0001)$. Remission of diabetes $\left(\mathrm{HbA}_{1 \mathrm{c}}\right.$ $<6.5 \%)$ occurred in 12 of 18 patients (67\%) at 3 months, 20 of $27(74 \%)$ at 6 months and 21 of 25 (84\%) at 12 months; of 41 patients under glucose-lowering treatment, 26 (63\%)
\end{abstract}

achieved complete withdrawal of treatment and 7 (17\%) had their doses reduced. The mean of differences between baseline and 12-month measurements of systolic BP was $10.5 \mathrm{~mm}$ $\mathrm{Hg}(\mathrm{p}=0.021)$ and the total-to-HDL cholesterol ratio $0.9(\mathrm{p}<$ 0.002). Conclusion: Our study confirmed the finding of previous studies that gastric bypass surgery in obese people with $T 2 D$ results in significant weight loss, and improved glycaemic, BP and lipid profiles. Bariatric surgery should be regarded as an effective therapeutic intervention in this patient population.

Copyright $\odot 2011$ S. Karger AG, Basel

\section{Introduction}

The twin epidemics of obesity and type 2 diabetes (T2D) have become major public health concerns worldwide. The vast majority of people with T2D are overweight and over half are clinically obese [1]. The benefits of even modest weight loss in favourably modifying glucose control and other cardiovascular risk factors such as lipid profile and blood pressure (BP) are already well known [2]. Over the last decade bariatric surgery has been increasingly recognized as an intervention of choice for achieving clinically significant and durable weight loss in morbidly obese people. Bariatric surgery also results in

\section{KARGER}

Fax +41613061234 E-Mail karger@karger.ch www.karger.com
(C) 2011 S. Karger AG, Base

$1011-7571 / 12 / 0212-0125 \$ 38.00 / 0$

Accessible online at:

www.karger.com/mpp
Dr. Akheel Syed

Department of Obesity Medicine, Endocrinology and Diabetes

Salford Royal NHS Foundation Trust and University Teaching Hospital

Salford M6 8HD (UK)

Tel. +44 161206 4625, E-Mail aas@ DrSyed.org 
resolution or improvement in the severity of several comorbid conditions including T2D, hypertension, hyperlipidaemia and obstructive sleep apnoea. Several series have reported that the majority of obese people with T2D who undergo bariatric surgery achieve remission of their diabetes or a significant reduction of their glucose-lowering therapy. However, uptake of bariatric surgery has been patchy in the UK despite clinical guidelines published by the National Institute for Health and Clinical Excellence in 2006. We hereby describe our experience of metabolic outcomes following Roux-en-Y gastric bypass surgery in people with T2D in Greater Manchester.

\section{Subjects and Methods}

A retrospective, observational cohort analysis of bariatric surgical patients in the setting of a National Health Service (NHS) university teaching hospital that serves the population of Greater Manchester in north-west England was carried out. Forty-nine obese people with T2D (31 women) who had undergone gastric bypass surgery 12 or more months previously were identified from electronic patient records. Pre-operative and postoperative body weight and glycosylated haemoglobin $\left(\mathrm{HbA}_{1 \mathrm{c}}\right)$ at 3, 6 and 12 months, and changes to glucose-lowering therapies were recorded. Weight loss outcomes were reported as percentage of excess body weight loss based on the degree of excess weight above the reference standard body mass index of 25 [3], computed by the formula [initial weight $(\mathrm{kg})$ - current weight $(\mathrm{kg})] /[$ initial weight $(\mathrm{kg})$ - ideal weight $(\mathrm{kg})] \cdot 100$, where ideal weight $(\mathrm{kg})=25 \cdot[$ height $(\mathrm{m})]^{2}$. BP and total and high-density lipoprotein (HDL) cholesterol measurements at baseline and 12 months postoperatively were also extracted. The primary outcome measure was change in $\mathrm{HbA}_{1 \mathrm{c}}$ following gastric bypass surgery; secondary outcomes included changes in glucose-lowering treatment, BP and lipid profile. Data were analysed with SPSS 16.0 (SPSS Inc., Chicago, Ill., USA) and Prism 4.03 (Graph Pad Software Inc., La Jolla, Calif., USA). Comparisons between paired measurements were performed by Student's paired-samples t test and proportions by Fisher's exact test. Comparisons among groups were done by oneway analysis of variance followed by Tukey's multiple comparison test. $p<0.05$ was considered statistically significant. To cope with missing values because of the retrospective, observational nature of the study, frequencies were reported as valid percentages to circumvent the problem of differing denominators. Data were reanalysed after imputing missing values by the expectation-maximization method to confirm significant results. Results were reported based on original, unimputed data.

\section{Results}

The mean \pm standard deviation (SD) of patients' age was $49.9 \pm 8.7$ years, pre-operative body weight $141.4 \pm$ $26.4 \mathrm{~kg}$ and body mass index $49.4 \pm 7.3$; the duration of diabetes was $9.1 \pm 5.1$ years and pre-operative $\mathrm{HbA}_{1 \mathrm{c}}$ $8.1 \pm 1.5 \%$. Of the 49 patients, $30(61 \%)$ were receiving oral hypoglycaemic agents whilst $11(22 \%)$ were on insulin with or without oral hypoglycaemic agents. Of $45 \mathrm{pa}-$ tients, $41(91 \%)$ had a pre-operative $\mathrm{HbA}_{1 \mathrm{c}} \geq 6.5 \%$. Preoperative mean systolic and diastolic $\mathrm{BP} \pm \mathrm{SD}$ were 147.0 \pm 20.2 and $80.6 \pm 12.6 \mathrm{~mm} \mathrm{Hg}$, respectively, total and HDL cholesterol $4.5 \pm 1.1$ and $1.2 \pm 0.3 \mathrm{mmol} / \mathrm{l}$, respectively, and the total-to-HDL cholesterol ratio $4.0 \pm 1.5$.

The mean postoperative percent excess body weight loss at 3, 6 and 12 months was 39.0, 53.9 and 71.1, respectively ( $\mathrm{p}<0.0001$ for trend; fig. 1a), with a corresponding fall in mean $\mathrm{HbA}_{1 \mathrm{c}}$ to $6.63,6.22$ and $5.78 \%$, respectively ( $p<0.0001$ for trend; fig. 1b). Remission of diabetes, defined as an $\mathrm{HbA}_{1 \mathrm{c}}<6.5 \%$ with no glucose-lowering treatment, occurred in 12 of 18 patients (67\%) by 3 months, 20 of $27(74 \%)$ by 6 months and 21 of $25(84 \%)$ by 12 months (baseline vs. 12 months, $\mathrm{p}<0.0001)$. The mean duration of diabetes \pm SD was $9.0 \pm 4.5$ years in patients who achieved remission of T2D by 1 year compared to $17.0 \pm$ 3.5 years in those who did not. Of 41 patients who were on glucose-lowering treatment pre-operatively, 26 (63\%) achieved complete withdrawal of treatment and 7 (17\%) had their medication doses reduced. Of 11 patients who were on insulin with or without oral hypoglycaemic agents pre-operatively, 7 (64\%) came off insulin treatment and 4 (36\%) had their medication doses reduced; 5 (46\%) achieved complete withdrawal of glucose-lowering treatment.

The mean of differences between baseline and 12-month measurements of systolic BP was $10.45 \mathrm{~mm} \mathrm{Hg}$ $(\mathrm{p}=0.021$; fig. 1c), diastolic BP $2.62 \mathrm{~mm} \mathrm{Hg}(\mathrm{p}=0.431)$, total cholesterol $0.68 \mathrm{mmol} / \mathrm{l}(\mathrm{p}=0.014)$, HDL cholesterol $-0.15 \mathrm{mmol} / \mathrm{l}(\mathrm{p}<0.006)$, and the total-to-HDL cholesterol ratio 0.86 ( $p<0.002$; fig. 1d). Systolic BP was $>140$ $\mathrm{mm} \mathrm{Hg}$ in 27 of 40 patients (67.5\%) pre-operatively compared to 12 of $33(36.4 \%)$ postoperatively $(\mathrm{p}<0.01)$. The total-to-HDL cholesterol ratio was $>4.0$ in 18 of 40 patients (45\%) pre-operatively compared to 3 of $30(10 \%)$ postoperatively $(\mathrm{p}<0.002)$.

\section{Discussion}

Our observational study confirmed significant weight loss and early remission or improvement in T2D following gastric bypass surgery as shown in a recent large meta-analysis of studies involving more than 135,000 postbariatric diabetic patients [4]. The remission of glucose intolerance in T2D following gastric bypass surgery 
Fig. 1. Changes in percentage of excess body weight loss (EBWL; a), $\mathrm{HbA}_{\mathrm{lc}}$ (b), BP (c; $\mathbf{\square}=$ systolic $\mathrm{BP}, \mathbf{O}=$ diastolic $\mathrm{BP}$ ) and total-to-HDL cholesterol ratio (d) from baseline following Roux-en-Y gastric bypass surgery in obese people with T2D. Data points ( \pm error bars) represent means ( \pm standard error). ${ }^{*} \mathrm{p}<0.05$ : weight and $\mathrm{HbA}_{1 \mathrm{c}}$ trends, and change in systolic $\mathrm{BP}$ and total-to-HDL cholesterol were significant.

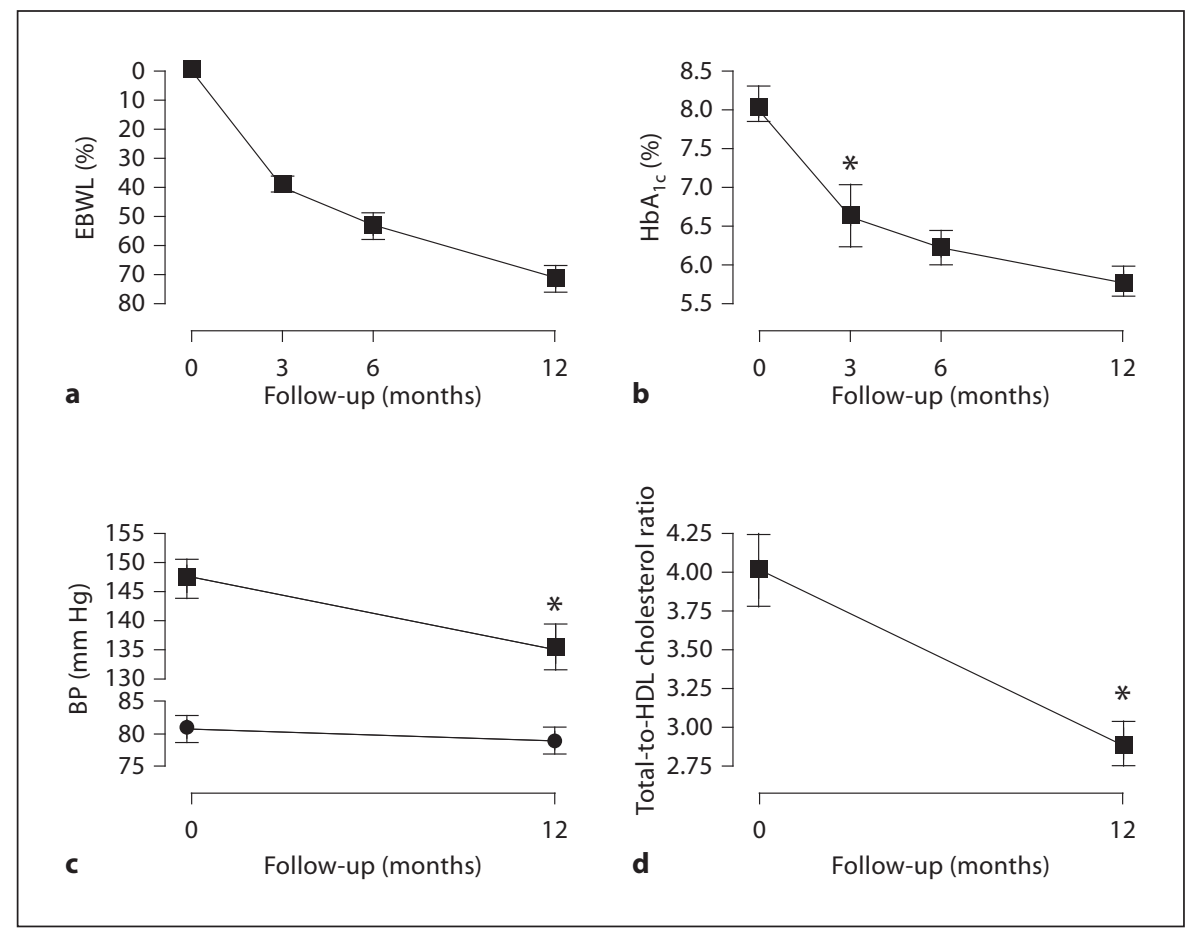

mostly occurs in the early postoperative period long before a clinically significant weight loss is observed, as also seen in our study. This implies that gastric bypass surgery improves diabetes through changes in the entero-insular axis, and various gut hormones and adipokines have been implicated. Ghrelin is an orexigenic hormone expressed mainly in the fundus of the human stomach that stimulates hunger. The plasma ghrelin concentration increases with diet-induced weight loss; however, gastric bypass surgery is associated with markedly suppressed ghrelin levels, possibly contributing to the weight-reducing effect of the procedure [5]. In contrast to ghrelin, glucagon-like peptide 1 (GLP-1) and peptide YY act as appetite suppressants [6]. GLP-1 and peptide YY are released in response to nutrient ingestion from endocrine L cells, which are most densely located in the distal ileum. It has been shown that gastric bypass is associated with a marked increase in GLP-1 and peptide YY plasma concentrations in response to nutrient ingestion [7]. There is emerging evidence from preclinical studies [8] that potentiation of GLP- 1 activity can increase $\beta$-cell mass, stimulate $\beta$-cell proliferation, increase $\beta$-cell neogenesis and inhibit $\beta$ cell apoptosis. Whilst this remains to be seen in clinical studies in humans, augmentation of GLP-1 by gastric bypass surgery raises the exciting possibility of reversal of diabetes disease progression.

Metabolic Outcomes after Bariatric Surgery
Our study confirmed that patients who achieved remission of T2D had a shorter duration of T2D compared to patients who did not. Patients with a longer duration of T2D are more likely to have progressed to significant $\beta$-cell failure that fails to improve after bariatric surgery. Other factors which predict remission of diabetes following bariatric surgery include younger age, shorter duration of diabetes and greater weight loss. A recent study has reported that percent excess body weight loss is the only predictor of remission of T2D that was influenced by the choice of the bariatric procedure, with a higher chance of remission with gastric bypass compared to gastric banding within 2 years of surgery [9]. Failure of resolution of T2D, on the other hand, can result from lack of patient concordance, inadequate weight loss, long-standing uncontrolled diabetes, or when the diabetes is actually type 1 but misclassified as T2D [10].

Our study confirmed reduction in systolic BP at 1 year following gastric bypass. It also confirmed a significant increase in HDL cholesterol as well as a reduction in total cholesterol and the total-to-HDL cholesterol ratio. Due to the practicalities of follow-up in standard NHS clinics, blood specimens were drawn in the non-fasting state and triglycerides and low-density lipoprotein cholesterol were not recorded in our cohort. The Swedish Obese Subjects (SOS) study, which compared 2,010 postbariatric patients

Med Princ Pract 2012;21:125-128 
with 2,037 non-surgical patients matched for age, sex, body mass index and comorbidities, demonstrated a reduction of $43 \%$ in myocardial infarction rate and $31 \%$ in overall mortality rate at 15 years of follow-up [11]. The SOS study also reported reductions in traditional risk factors for cardiovascular disease including hypertension and rates of dyslipidaemia (high triglyceride and low HDL cholesterol), but not hypercholesterolaemia, in the surgically treated group [12]. It is to be noted, however, that the SOS study included various surgical procedures, including gastric banding and the now obsolete vertical banded gastroplasty, and people with or without diabetes.

Based on our observation of early remission or improvement in T2D following gastric bypass surgery, we now routinely recommend cessation of glucose-lowering treatments in the immediate postoperative period in people with T2D prior to discharge from hospital, with subsequent intensive monitoring of capillary blood glucose concentrations and review by specialist nurses. As patients have markedly reduced food intake following gastric bypass surgery, our protocol minimizes the risk of postoperative hypoglycaemia. In the minority of patients who continue to manifest hyperglycaemia, glucose-lowering therapies may be re-introduced in a phased manner as clinically indicated.

A major limitation of our study is that we did not undertake special investigations to exclude auto-immune diabetes and as we accepted the classification of diabetes by the patient's primary physician. Whilst this is a potential drawback of our pragmatic, retrospective observational study, the remission rates of $\mathrm{T} 2 \mathrm{D}$ are comparable to the recent meta-analysis [4].

\section{Conclusion}

Gastric bypass surgery resulted in early remission or improvement in T2D, hypertension and hyperlipidaemia. Bariatric surgery should be regarded as an effective therapeutic intervention in the management of obese people with T2D.

\section{References}

1 Daousi C, Casson IF, Gill GV, MacFarlane IA, Wilding JP, Pinkney JH: Prevalence of obesity in type 2 diabetes in secondary care: association with cardiovascular risk factors. Postgrad Med J 2006;82:280-284.

-2 Pi-Sunyer X, Blackburn G, Brancati FL, Bray GA, Bright R, Clark JM, Curtis JM, Espeland MA, Foreyt JP, Graves K, Haffner SM, Harrison B, Hill JO, Horton ES, Jakicic J, Jeffery RW, Johnson KC, Kahn S, Kelley DE, Kitabchi AE, Knowler WC, Lewis CE, MaschakCarey BJ, Montgomery B, Nathan DM, Patricio J, Peters A, Redmon JB, Reeves RS, Ryan DH, Safford M, Van Dorsten B, Wadden TA, Wagenknecht L, Wesche-Thobaben J, Wing RR, Yanovski SZ: Reduction in weight and cardiovascular disease risk factors in individuals with type 2 diabetes: one-year results of the look ahead trial. Diabetes Care 2007; 30:1374-1383.

3 Bray GA, Bouchard C, Church TS, Cefalu WT, Greenway FL, Gupta AK, Kaplan LM, Ravussin E, Smith SR, Ryan DH: Is it time to change the way we report and discuss weight loss? Obesity 2009;17:619-621.
4 Buchwald H, Estok R, Fahrbach K, Banel D, Jensen MD, Pories WJ, Bantle JP, Sledge I: Weight and type 2 diabetes after bariatric surgery: systematic review and meta-analysis. Am J Med 2009;122:248-256, e245.

5 Cummings DE, Weigle DS, Frayo RS, Breen PA, Ma MK, Dellinger EP, Purnell JQ: Plasma ghrelin levels after diet-induced weight loss or gastric bypass surgery. N Engl J Med 2002;346:1623-1630.

6 Badman MK, Flier JS: The gut and energy balance: visceral allies in the obesity wars. Science 2005;307:1909-1914.

7 Morinigo R, Moize V, Musri M, Lacy AM, Navarro S, Marin JL, Delgado S, Casamitjana R, Vidal J: Glucagon-like peptide-1, peptide YY, hunger, and satiety after gastric bypass surgery in morbidly obese subjects. J Clin Endocrinol Metab 2006;91:1735-1740.
8 Vilsboll T: The effects of glucagon-like peptide- 1 on the beta cell. Diabetes Obes Metab 2009;11(suppl 3):11-18

9 Hamza N, Abbas MH, Darwish A, Shafeek Z, New J, Ammori BJ: Predictors of remission of type 2 diabetes mellitus after laparoscopic gastric banding and bypass. Surg Obes Relat Dis 2010, E-pub ahead of print.

10 Deitel M: Update: why diabetes does not resolve in some patients after bariatric surgery. Obes Surg 2011;21:794-796.

$>11$ Sjostrom L, Narbro K, Sjostrom CD, Karason K, Larsson B, Wedel H, Lystig T, Sullivan M, Bouchard C, Carlsson B, Bengtsson C, Dahlgren S, Gummesson A, Jacobson P, Karlsson J, Lindroos AK, Lonroth H, Naslund I, Olbers T, Stenlof K, Torgerson J, Agren G, Carlsson LM: Effects of bariatric surgery on mortality in Swedish obese subjects. N Engl J Med 2007;357:741-752.

12 Sjostrom L: Bariatric surgery and reduction in morbidity and mortality: experiences from the SOS study. Int J Obes (Lond) 2008; 32(suppl 7):S93-S97. 